\section{Marketization of Home}

\section{Production and Gender}

\section{Gaps in Working Hours}

Robert Duval-Hernández, Open University of Cyprus, CIDE, and IZA

Lei Fang, Federal Reserve Bank of Atlanta

L. Rachel Ngai, London School of Economics, CEPR, and CfM

\section{Summary:}

Gender gaps in working hours vary widely across member countries of the Organisation for Economic Co-operation and Development. This article summarizes the key results from Duval-Hernández, Fang, and Ngai (2021), who study the source of cross-country differences and what kind of policies can reduce the gap in working hours between women and men.

\section{Key findings:}

1. Cross-country differences in the gender ratio of market hours (women relative to men) are mostly accounted for by the differences in market hours of women and the size of the service sector that produces close substitutes to home production.

2. Cross-country differences in taxes and social subsidies on family care can help explain the differences of the gender ratio in market hours.

3. The key to increase female market hours is to establish policies that reduce the cost of marketizing home production.

\section{Center affiliation: Center for Human Capital Studies}

JEL classification: E24, E62, J22

Key words: gender ratio, market hours, subsidies for family care, taxes, home production, marketization

\section{https://doi.org/10.29338/ph2021-07}

CENTER FOR QUANTITATIVE

ECONOMIC RESEARCH

\section{CENTER FOR HUMAN CAPITAL STUDIES}

CENTER FOR FINANCIAL INNOVATION AND STABILITY

CENTER FOR HOUSING AND POLICY

ECONOMIC RESEARCH SURVEY CENTER

AMERICAS CENTER

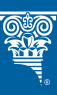

Federal Reserve Bank of Atlanta

The Federal Reserve Bank of Atlanta's Policy Hub

leverages the expertise of Atlanta Fed economists and researchers to address issues of broad policy interest.

Our research centers coordinate this work and seek to influence policy discussions. Areas of interest include: forecasting, fiscal policy, and macroeconomics (Center for Quantitative Economic Research); financial stability, innovation, and regulation (Center for Financial Innovation and Stability); human capital, labor markets, health, and education (Center for Human Capital Studies); and government-sponsored entity reform, mortgage markets, and affordable housing (Center for Housing and Policy). Sign up for email updates at frbatlanta.org/research/publications/ policy-hub. 


\section{Marketization of Home}

\section{Production and Gender Gaps in Working Hours}

Summary: Gender gaps in working hours vary widely across member countries of the Organisation for Economic Co-operation and Development. This article summarizes the key results from DuvalHernández, Fang, and Ngai (2021), who study the source of cross-country differences and what kind of policies can reduce the gap in working hours between women and men.

\section{About the Authors:}

Robert Duval-Hernández is an Assistant Professor at the Faculty of Economics and Management at the Open University of Cyprus. His research areas are labor economics and development economics.

Lei Fang is a research economist and associate adviser on the macroeconomics and monetary policy team in the Research Department of the Federal Reserve Bank of Atlanta. Her research areas are macroeconomics, growth and development economics, and labor economics.

L. Rachel Ngai is an associate Professor at London School of Economics. Her research areas are macroeconomics and labor economics.

Acknowledgments: The views in this article represent those of the authors and are not those of either the Federal Reserve Bank of Atlanta or the Federal Reserve System. We acknowledge financial support from the European Research Council EUROEMP Advanced Grant (\#323940) administered by the University of Cyprus. Author contacts: robert.duval@ouc.ac.cy, lei.fang@atl.frb.org, and L.Ngai@Ise.ac.uk.

Comments to the authors are welcome at Lei.Fang@atl.frb.org. 


\section{Introduction}

Gender gaps in working hours per adult vary widely across member countries of the Organisation for Economic Co-operation and Development (OECD). Our paper (Duval-Hernández, Fang, and Ngai 2021) attempts to understand the source of cross-country differences and what kind of policies can reduce the gap in working hours between women and men. Using household surveys from 17 OECD countries, we find that the cross-country differences in the ratio of market hours of women relative to men are mostly accounted for by the cross-country differences in market hours of women, especially women without college degrees. Moreover, a comparison of market hours by sector reveals that, along the sectoral dimension, the cross-country differences in the gender ratio of market hours is mainly accounted for by the size of the service sector that produces close substitutes to home production.

To understand the gender gaps in market hours, it is crucial to differentiate between nonmarket hours devoted to home production and leisure hours. A recent publication by Addati, Cattaneo, Esquivel, and Valarino (2018) from the International Labour Organization reveals that the hours devoted to home production by women are triple that of men, and for women, the need of household work is the main self-reported barrier to enter the labor market. Unlike leisure hours, home production can be outsourced by purchasing close substitutes from the corresponding market service sectors. This outsourcing process is called the marketization of home production. Marketization converts home production hours into market hours and is especially relevant for women, since the production of these service tends to be female intensive. ${ }^{1}$ Thus, factors that determine the extent of marketization can have important implications for the labor market outcomes by gender.

Using the income and consumption taxes constructed by McDaniel (2007) and subsidies on family care from the OECD Social Expenditure Database, we document that taxes are negatively correlated with gender hour ratios (women relative to men) for both college graduates and non-college graduates. In contrast, subsidies on family care display the opposite correlation with such gender ratios. These correlations mainly reflect the marketization of home production, which primarily affects women and the sector that produce close substitutes to home production.

Our study has implications for the types of policies that can be used to promote the participation of women in the labor market. For instance, the International Labour Organization (2016) documents that the gender gap in employment is much larger in many developing countries, and as in the case of the United States and Europe, women do most of the housework. That report also suggests that higher government spending on family policies - such as social care services, policies on family leave, and family-friendly work schedules-are associated with higher female employment-topopulation ratios. This finding is consistent with our own finding that the key to increased female market hours is establishing policies that reduce the cost of marketizing home production.

\section{Cross-Country Differences in Market Hours}

Gender Ratio in Market Hours. Figure 1 plots the gender ratio in market hours (female relative to male) by country relative to the values observed in the United States. In most countries, the ratio is smaller than in the United States for both education groups. The average deviation from the United States in Western and Southern Europe is -0.05 and -0.15 for those with and without a college degree,

\footnotetext{
${ }^{1}$ The closure of many of these market sectors during the recent COVID-19 pandemic has shown a disproportional impact on female market work around the world (see International Labour Organization 2021).
} 
respectively. In Nordic countries the gender hour ratios are close to the ones observed in the United States.

Figure 1: Gender Ratios in Market Hours and Wages Relative to the U.S.

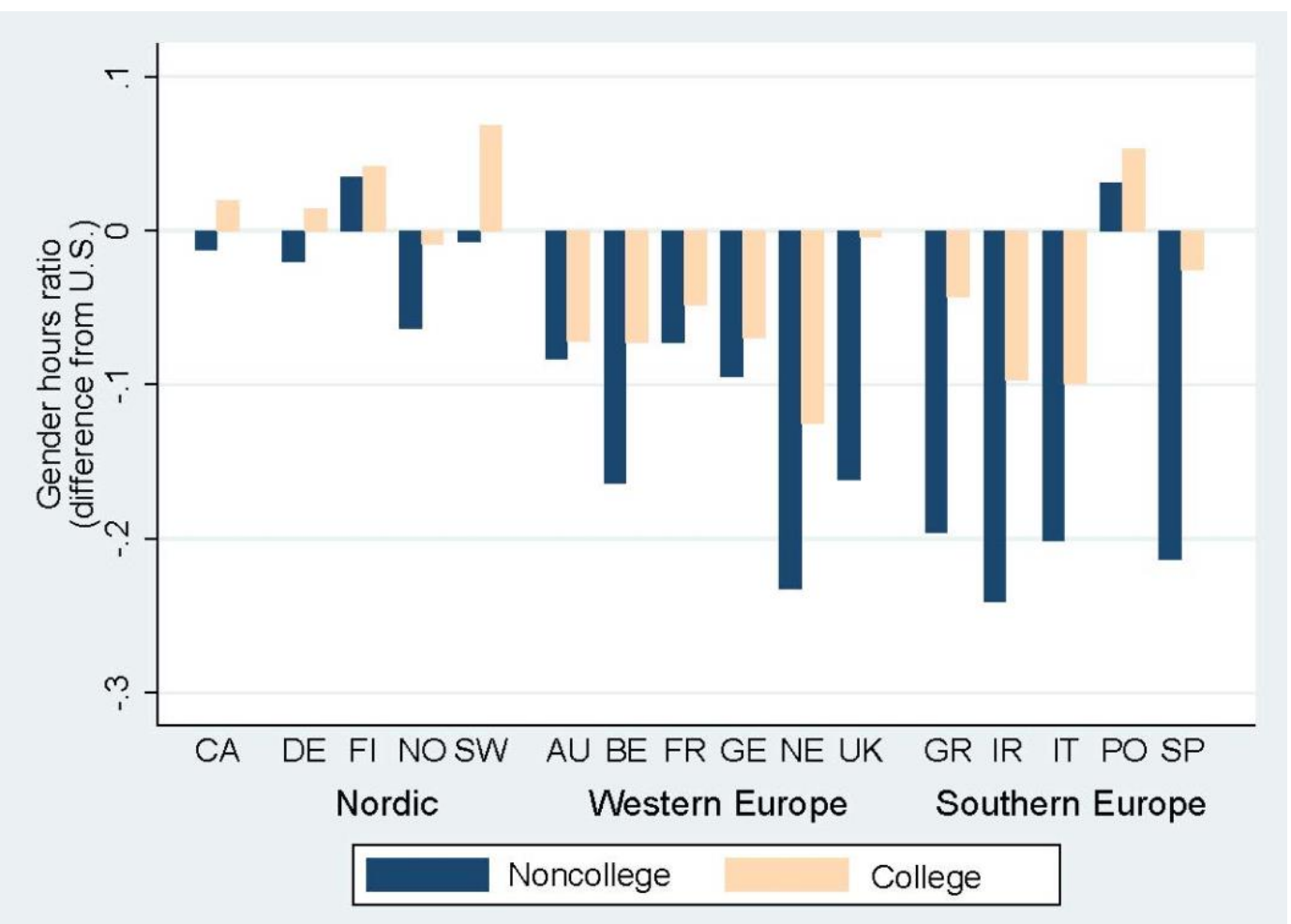

Note: Market hours are constructed using the standardized EU Labor Force Survey for European countries from the March supplement of the Current Population Survey for the United States and the population census for Canada. The sample includes individuals between the ages of 20 and 64 . The average hours worked per person are derived as the total annual working hours divided by the number of individuals.

Market Hours by Gender and Education. Figure 2 presents the percentage difference in annual hours worked per adult relative to the United States by gender-education group. ${ }^{2}$ Market hours of every gender-education group are lower in Europe than in the United States. In most of the countries, the largest proportional differences occur for women without a college degree, and the differences are larger for women than for men with the same education level. In Western and Southern European countries, on average 40 percent of the difference in market hours is accounted for by the hours of women without a college education, and 60 percent by women in total. In the Nordic countries, Canada, and Portugal, women without a college degree account for one-fifth of the difference, and women in total account for 40 percent.

\footnotetext{
2 In all of our analyses, we group Ireland with southern European countries based on the similarity of these countries' labor supply of women.
} 
Figure 2: Hours Worked in the Market by Population Group Relative to the U.S.

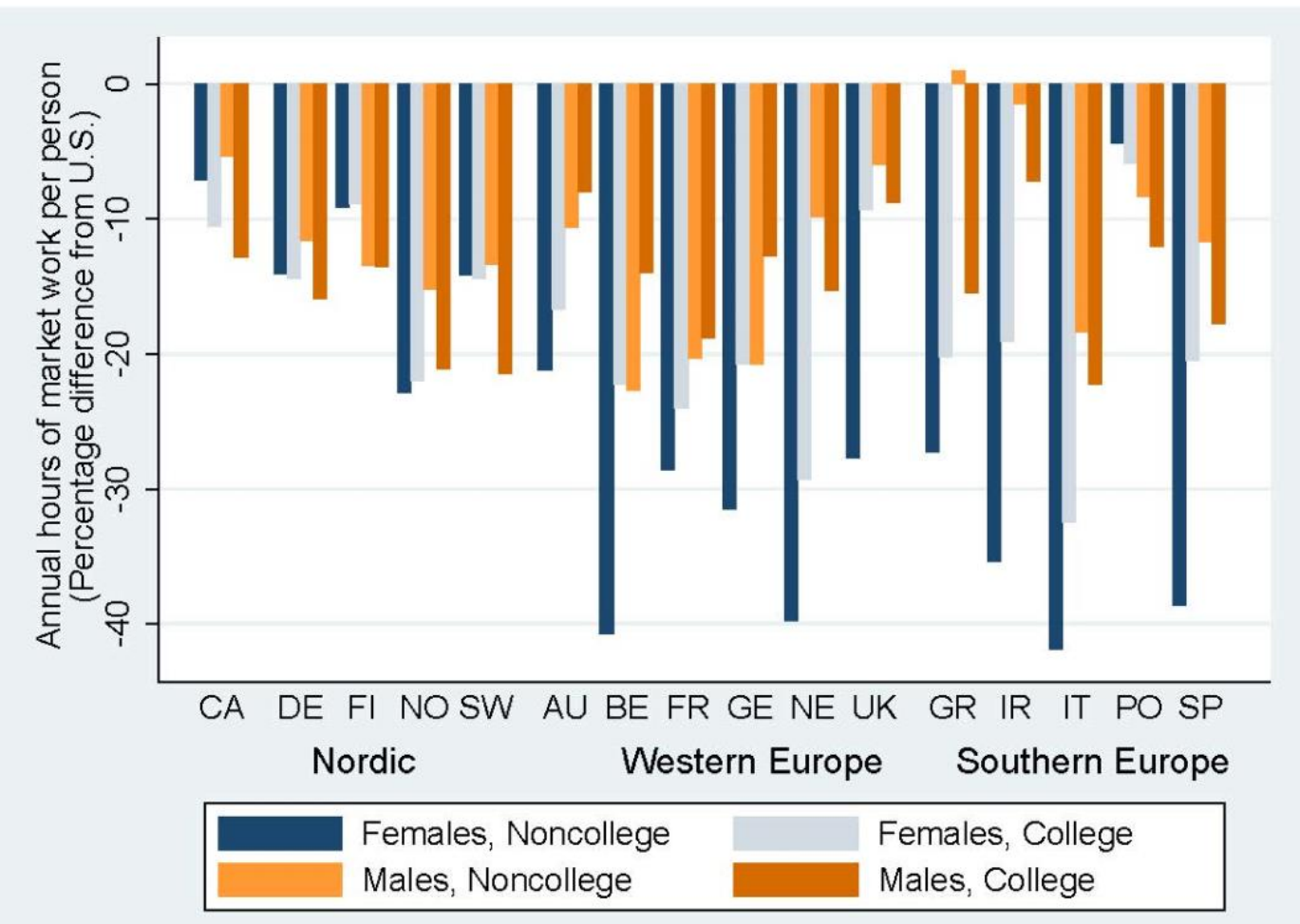

Note: Market hours are constructed using the standardized EU Labor Force Survey for European countries from the March supplement of the Current Population Survey for the United States and the population census for Canada. The sample includes individuals between the ages of 20 and 64. The annual average hours worked per person are derived as the total annual working hours divided by the number of individuals.

Market Hours by Sector. We divide market production into three sectors: goods, nonsubstitutable services, and substitutable services. Broadly speaking, a service industry is classified as "substitutable" if its product can be replaced by activities performed at home. Figure 3 displays the proportional differences in sectoral hours relative to the United States. For most countries, hours in all three sectors are lower than their counterparts in the United States and the largest difference occur for the substitutable service sector. In most Western and southern European countries, more than 40 percent of the aggregate difference is accounted for by the substitutable service sector; while in Nordic countries and Canada this fraction is one-third and one-fifth, respectively. 
Figure 3: Hours Worked by Sector Relative to the U.S.

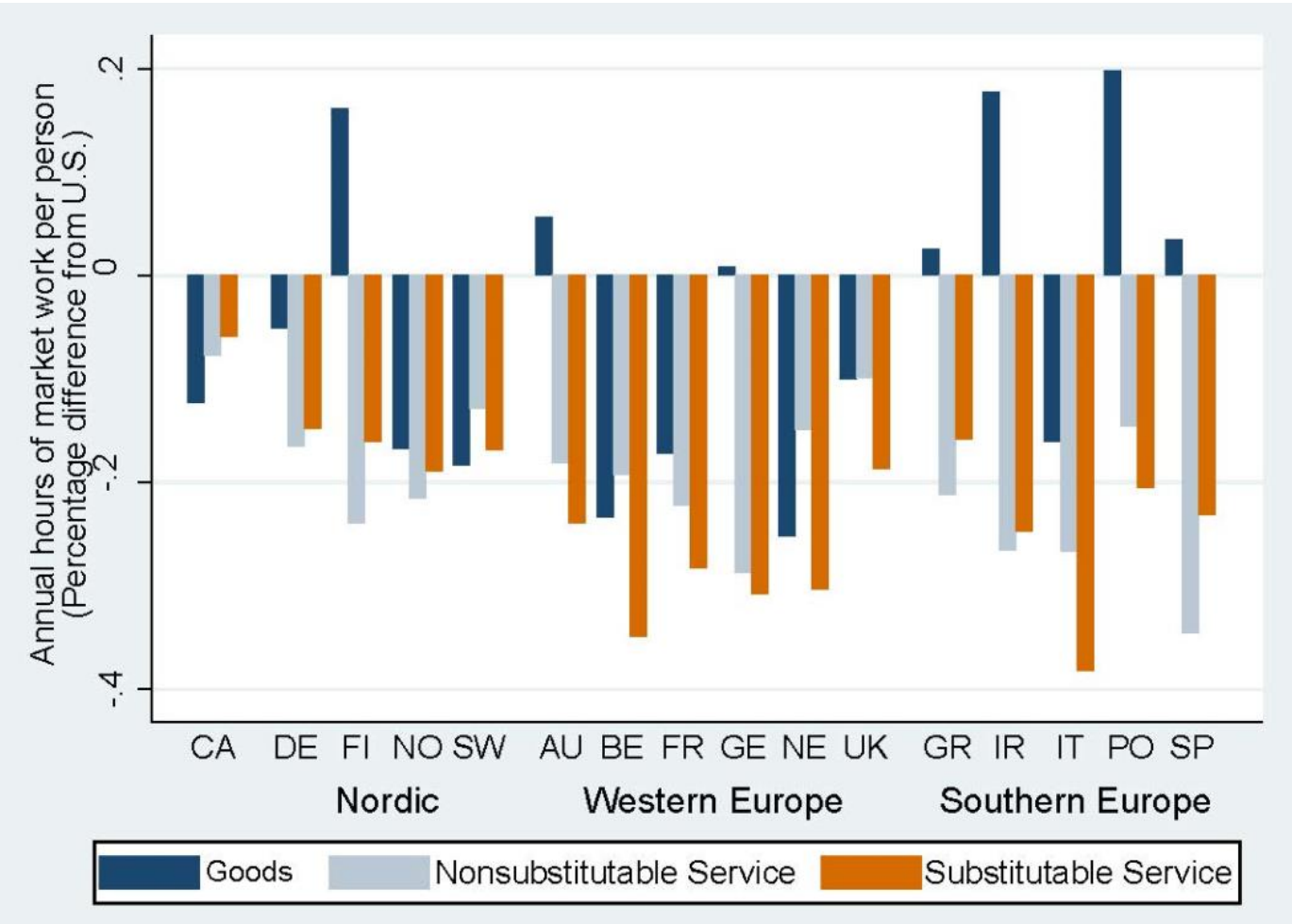

Note: Market hours are constructed using the standardized EU Labor Force Survey for European countries from the March Supplement of the Current Population Survey for the United States and the population census for Canada. The substitutable service sector includes retail trade, hotels and restaurants, health and social work, personal and community services, and domestic services hired by households.

\section{Marketization and Policies}

In Duval-Hernández, Fang, and Ngai (2021), we also studied how the gender ratio in market hours related to taxes and social subsidies on family care. The tax measure includes labor income and consumption taxes. Social subsidies include public noncash benefits (also called "in-kind" expenditures) on old-age, incapacity, and family care services. The main care items covered under these categories include residential care, home-help services, rehabilitation, day care, and early childhood education.

We find a negative association between taxes and gender ratios in market hours for both college graduates and non-college graduates and find the opposite for subsidies. More importantly, we find that taxes and subsidies affect gender ratios in market hours mainly through their effects on the substitution between home production hours and market hours for women. Lower taxes increase the benefit of market work relative to home production and induce households to work more in the market. Because women spend more time on home production, the effect is stronger for women than for men. Hence, lower taxes disproportionally increase female marker hours and therefore reduce the gap from men. The United States has the lowest tax rate among the countries studied and thus has the smallest gender gap in market hours. Similarly, higher social subsidies on family care reduce the cost of outsourcing home production and free up women's time, thus enabling women to work more in the market. Nordic countries have the highest spending on subsidizing family care services, which helps to explain the small difference in their gender ratios from the United States. 
We also find that market hours in all three market sectors are negatively correlated with taxes and that the largest negative association occurs for the substitutable service sector. Subsidies are positively related to market hours in the substitutable service sector and the estimates for other sectors are statistically insignificant. These results are not surprising since substitutable services and homeproduced services are close substitutes, and therefore the effects of policies through the marketization channel have a larger impact on the substitutable services sector than the other two sectors.

\section{Conclusion}

Gender gaps in working hours vary widely across OECD countries. In our paper Duval-Hernández, Fang, and Ngai (2021), we find that the cross-country differences in the gender ratio of market hours (women relative to men) are mostly accounted for by the differences in market hours of women and the size of the service sector that produces close substitutes to home production. We show that cross-country differences in taxes and social subsidies on family care can help explain the differences in this gender ratio. Our studies imply that a key to increasing female market hours is to establish policies that reduce the cost of marketizing home production.

\section{References}

Addati, Laura, Umberto Cattaneo, Valeria Esquivel, and Isabel Valarino. 2018. Care work and care jobs: For the future of decent work. Technical report, International Labour Organization.

Duval-Hernández, Robert, Lei Fang, and Rachel Ngai. 2021. Taxes, subsidies, and gender gaps in hours and wages. Atlanta Fed working paper no. 2021-17.

International Labour Organization. 2016. Women at Work. Trends 2016, International Labour Office, Geneva.

- - ILO Monitor. 2021. COVID-19 and the world of work (multiple editions). https://www.ilo.org/global/topics/coronavirus/impacts-and-responses/WCMS_767028/lang-en/index.htm

McDaniel, Cara. 2007. Average tax rates on consumption, investment, labor and capital in the OECD 1950-2003. Unpublished manuscript. 